\section{De toda maneira tem que andar junto: ações intersetoriais entre saúde e educação para crianças vivendo com a síndrome congênita do vírus Zika}

The need to act together in every way possible: inter-sector action in health and education for children living with the congenital Zika syndrome

De todas formas deben ir juntas de la mano: acciones intersectoriales entre salud y educación para niños que viven con el síndrome congénito del virus Zika
Miriam Ribeiro Calheiros de Sá 1

Ana Carolina Dias Vieira 1

Barbara S. Madeira Castro 1

Olivia Agostini 1

Tracey Smythe 2

Hannah Kuper 2

Maria Elisabeth Lopes Moreira 1

Martha Cristina Nunes Moreira 1

\title{
Resumo
}

Com base na experiência de um programa de intervenção para famílias de crianças com a síndrome congênita do vírus Zika, que inclui múltiplas deficiências, em uma instituição de educação, foram observados os desafios e conquistas encontrados com a entrada dessas famílias no sistema escolar. $O$ objetivo deste artigo foi explorar os achados de pesquisa realizada após a conclusão de um programa de intervenção mediante entrevistas semiabertas com profissionais da instituição, e as possíveis contribuições para a construção das relações intersetoriais visando à inclusão escolar de crianças com deficiência. É possível constatar uma mudança provocada pelo programa na relação entre as famílias e os profissionais da instituição de educação; as famílias tiveram espaço para elaborar seus receios e discutir o papel da escola na vida de crianças com deficiência. Dessa forma, os profissionais passaram a vê-las em uma posição mais ativa. Acredita-se que esta experiência possa favorecer outros serviços e municípios que busquem a inclusão escolar de crianças e adolescentes com deficiência assim como sua inclusão social e de suas famílias.

Criança; Zika Vírus; Pessoas com Deficiência; Colaboração Intersetorial

\author{
Correspondência \\ M. R. C. Sá \\ Rua Marechal Raul de Albuquerque 273, apto. 705, Niterói, RJ \\ 24370-025, Brasil. \\ calheirosa@uol.com.br \\ 1 Instituto Nacional de Saúde da Mulher, da Criança e do \\ Adolescente Fernandes Figueira, Fundação Oswaldo Cruz, \\ Rio de Janeiro, Brasil. \\ 2 London School of Hygiene and Tropical Medicine, \\ London, U.K
}




\section{Introdução}

Este artigo retoma o lugar de crianças que vivem com múltiplas deficiências, em virtude das repercussões da síndrome congênita do vírus Zika, marca da epidemia de Zika de 2015. Essa síndrome comporta microcefalia e/ou outras alterações do sistema nervoso central associados à infecção pelo vírus 1,2 . Ela afeta o desenvolvimento global, com alterações consideráveis nas aquisições motoras, visuais, de alimentação e cognição, impondo uma vida com condições crônicas complexas de saúde 3,4. Suas necessidades ultrapassam as respostas oferecidas pelo sistema de saúde. Necessitam de ações intersetoriais, de políticas compensatórias inclusivas que enfrentem processos de vulnerabilidade. Os obstáculos que historicamente são vividos por outras crianças com condições de saúde raras, crônicas e complexas já são enfrentados hoje pelas crianças com síndrome congênita do vírus Zika. Tal complexidade justifica conhecimentos e práticas operando como uma rede de ações complementares e longitudinais, na sinergia entre os setores da saúde, educação, assistência social, direito, dentre outros. Carmo \& Guizard ${ }^{5}$ destacam a multideterminação da vulnerabilidade e a multiplicidade de fatores que as determinam, conjugando a ausência (ou precariedade) de acesso à renda, as fragilidades de vínculos afetivo-relacionais e a desigualdade de acesso a bens e serviços públicos.

Como nos lembra Diniz 6, se a emergência sanitária se extinguiu, a humanitária se instalou, tendo em conta as repercussões sociais e econômicas que são de natureza tardia e duradoura. A deficiência e a pobreza são entendidas como elementos que interagem entre si, formando um ciclo. O desenvolvimento de uma criança com deficiências se torna desafiador, implicando oferecer oportunidades para além dos processos de reabilitação, em um círculo virtuoso, com ações em outras esferas do cuidado na direção da intersetorialidade e integralidade 7,8 .

Mattos 9 confere três conjuntos de sentido à integralidade: atributo das práticas dos profissionais de saúde, organização dos serviços e resposta governamental via políticas voltadas para grupos populacionais específicos. O último atributo se liga intrinsicamente ao debate aqui empreendido no que toca ao grupo das crianças vivendo com múltiplas deficiências em função da síndrome congênita do vírus Zika. Políticas de caráter intersetorial precisam de articulações e arranjos por meio de parcerias entre diferentes setores e segmentos sociais como: educação, saúde, cultura, esporte, lazer, empresas privadas, organizações não governamentais $(\mathrm{ONG})$, fundações, entidades religiosas, as três esferas de governo e organizações comunitárias 10,11.

Desafiando as perspectivas, tem-se hoje crianças com a síndrome congênita do vírus Zika vivendo com múltiplas deficiências, que encontram uma precariedade em termos de rede intersetorial articulada e pronta para recebê-las. As experiências nacionais apontam que o epicentro da epidemia foi o Nordeste do Brasil, seguido da Região Sudeste ${ }^{1}$. Nessas regiões, determinados estados ganham destaque, e as capitais com maiores recursos se tornam locais de confluência de famílias em busca de atenção especializada e de reabilitação. Esse fenômeno aconteceu em Recife na relação com Pernambuco 12, e com a cidade do Rio de Janeiro em relação à região metropolitana desse estado. No Estado do Rio de Janeiro 13, essa multiplicidade de serviços se dispersa na atenção insuficiente à saúde e educação de crianças com deficiência em geral. Essa desarticulação opera mais como ações e serviços prestados multissetorialmente, planejados por um único setor ou equipamento social, sem coordenação. Silva \& Rodrigues 14 apontam uma falta de consenso entre os setores da saúde, educação e assistência social, o que se caracteriza como entrave que se opõe ao desenvolvimento de ações intersetoriais.

Neste artigo, ilumina-se a experiência de construção de um projeto intersetorial, centrado na relação entre saúde e educação, articulando as famílias com crianças vivendo com a síndrome congênita do vírus Zika, e ações de capacitação para os profissionais de educação que atuam com elas. $\mathrm{O}$ princípio da integralidade, focalizando crianças com deficiências em que se identificam as crianças com a síndrome congênita do vírus Zika, depende de dispositivos intersetoriais que articulem atenção especializada à saúde, reabilitação, atenção básica, além da inclusão no ambiente escolar.

Situada em uma pesquisa maior, aprovada sob o número de registro CAAE 70525217.5.1001.5269, aqui se foca a experiência do Programa JUNTOS e as possíveis contribuições para a construção das relações intersetoriais visando à inclusão escolar de crianças com múltiplas deficiências nascidas com a síndrome congênita do vírus Zika. 


\section{Antecedentes da pesquisa: de um projeto internacional de atuação com crianças com paralisia cerebral ao Programa JUNTOS}

Antecede a pesquisa que subsidia este artigo um projeto que, de agosto de 2017 a julho de 2018, desenvolveu-se entre a London School of Hygiene \& Tropical Medicine (LSHTM; Londres, Reino Unido), o Instituto Nacional de Saúde da Mulher, da Criança e do Adolescente Fernandes Figueira, Fundação Oswaldo Cruz (IFF/Fiocruz) e o Instituto de Saúde Coletiva, Universidade Federal da Bahia (ISC/ UFBA). O projeto objetivou adaptar e validar um programa preexistente, desenvolvido pela LSHTM em países da África e Ásia para crianças com paralisia cerebral e suas famílias 15 às especificidades da síndrome congênita do vírus Zika e desenvolvê-lo como complemento dos serviços clínicos e outros disponíveis no Brasil e nos demais países endêmicos do Zika vírus.

Tal projeto de adaptação se desdobrou em um programa de base intersetorial denominado JUNTOS, proposto para ocorrer ao longo de 10 semanas - com três grupos diferentes nesta primeira fase - cada um com uma média de sete famílias. Em cada uma dessas semanas, um tema diferente era abordado, tendo como facilitadoras do grupo sempre uma profissional de saúde e uma mãe de criança com síndrome congênita do vírus Zika. O objetivo desse programa é apoiar as famílias para que possam tecer redes de apoio em suas comunidades, além de dar suporte para o desenvolvimento físico e nutricional de suas crianças. A Figura 1 sintetiza esse movimento que parte de um programa de adaptação de um instrumento internacional, alcança o desenvolvimento do Programa JUNTOS e antecede à pesquisa que subsidia este artigo.

Na validação do projeto no Rio de Janeiro, três grupos foram formados: dois (um deles piloto) realizados no centro do Município do Rio de Janeiro e um terceiro no Município de São João de Meriti pela aproximação entre o IFF/Fiocruz e o Centro de Atendimento Educacional Especializado (CAEE) (Figura 2).

O Município de São João de Meriti se localiza na Baixada Fluminense, Região Metropolitana do Rio de Janeiro. Atualmente, possui 12 creches municipais, 4 escolas com atendimento exclusivo para educação infantil e 33 escolas com educação infantil, além de outros segmentos.

De fevereiro a junho de 2018, estiveram presentes semanalmente no CAEE uma equipe de 4 pesquisadoras, as famílias e os voluntários da sala de estimulação. Todos os profissionais do núcleo experimentaram uma aproximação com as crianças com a síndrome congênita do vírus Zika e suas famílias (Quadro 1).

Ao longo das semanas, as famílias passaram a ocupar o CAEE para frequentar o Programa JUNTOS. Com isso elas puderam se familiarizar com o espaço e observar, agora com profissionais do IFF/Fiocruz presentes, como era seu funcionamento. O programa propunha a discussão de variados temas, as famílias podiam falar sobre sua angústia em deixar seus filhos com "estranhos", porém ao longo do programa, percebendo a interação das crianças com os voluntários na sala de estimulação, foram notados os benefícios obtidos com essas novas relações. A aproximação provocou a inclusão escolar de crianças com a síndrome congênita do vírus Zika e paralisia cerebral em 9 das 12 creches existentes no município, mesmo onde não havia a presença de profissionais mediadores. Inicialmente, as mães desempenharam o papel de aproximação do corpo docente e do discente com seus filhos, participando das rotinas e ensinando às equipes de educadores a compreensão de suas demandas. Atualmente, das crianças que frequentam o polo do CAEE, 9 estão inseridas em diferentes creches municipais.

Paralelamente, foram realizados alguns encontros com as equipes de educadores e diretores das 12 creches do município, no intuito de aproximar e esclarecer suas dúvidas quanto às condições clínicas das crianças, orientações de cuidados, dentre outras. 


\section{Figura 1}

Esquema demonstrativo das instituições envolvidas na validação do Programa JUNTOS.

PROJETO INICIAL

Adaptação e validação de um programa pré-existente desenvolvido pela LSHTM em países da África e Ásia para crianças com paralisia cerebral e suas famílias.

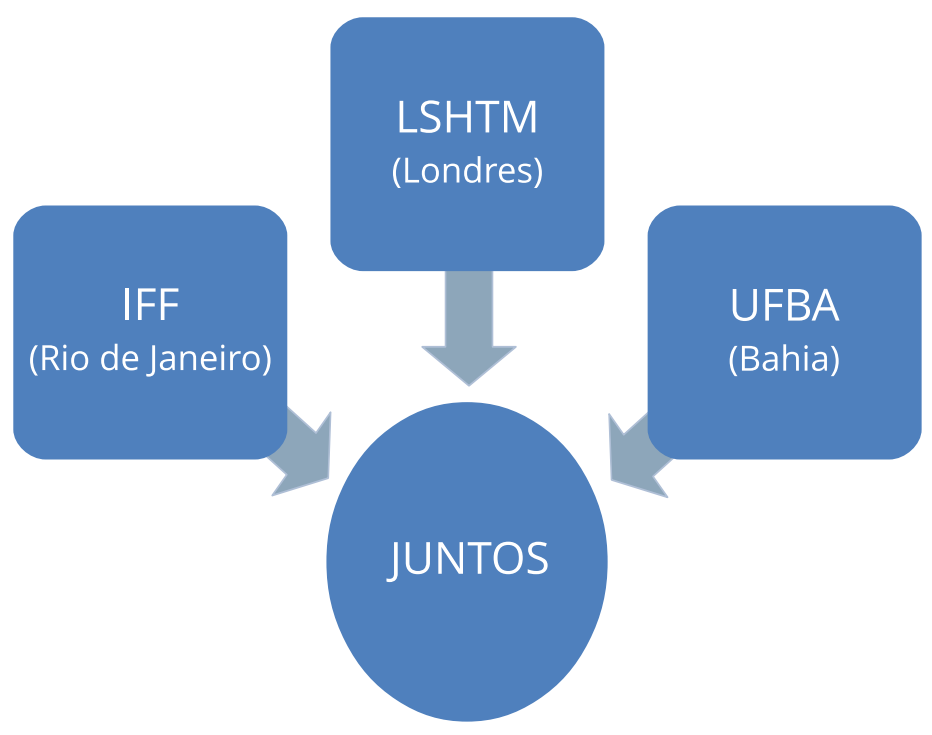

IFF: Instituto Nacional de Saúde da Mulher, da Criança e do Adolescente Fernandes Figueira; LSHTM: London School of Hygiene \& Tropical Medicine; UFBA: Universidade Federal da Bahia. 


\section{Figura 2}

Grupos formados para a validação do Programa JUNTOS.

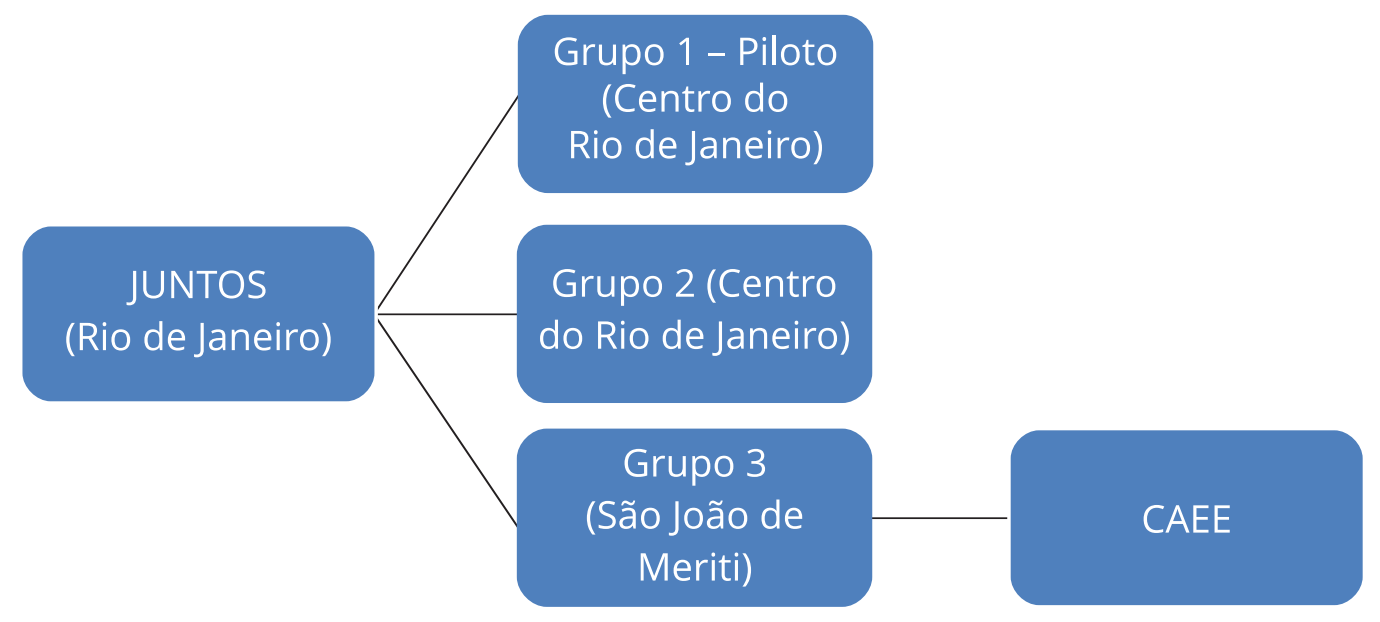

CAEE: Centro de Atendimento Educacional Especializado.

\section{Quadro 1}

Agentes sociais envolvidos no Programa JUNTOS em São João de Meriti, Rio de Janeiro, Brasil.

\begin{tabular}{|l|c|c|}
\hline Agentes sociais envolvidos em São João de Meriti & \multicolumn{2}{|c|}{ Qualificação/Área de atuação } \\
\hline $\begin{array}{l}\text { Pesquisadoras do Instituto Nacional de Saúde da Mulher, da } \\
\text { Criança e do Adolescente Fernandes Figueira }\end{array}$ & 4 & Psicólogos, fisioterapeuta, terapeuta ocupacional, mãe facilitadora \\
\hline Famílias & 7 & Mães, pais, tias, avós \\
\hline Voluntários & 4 & Alunos de psicopedagogia de uma universidade local \\
\hline $\begin{array}{l}\text { Profissionais do Centro de Atendimento Educacional Especializado } \\
\text { presentes nos dias em que o programa acontecia }\end{array}$ & 7 & Psicopedagogas, assistente social, fonoaudiólogas, pedagogas \\
\hline
\end{tabular}

\section{Metodologia}

A fim de possibilitar uma reflexão sobre o alcance do Programa JUNTOS, considerando a articulação realizada entre as famílias de crianças com síndrome congênita do vírus Zika e os setores da saúde e da educação, foi proposta uma pesquisa buscando acessar os sentidos das experiências dos profissionais envolvidos no Programa. De caráter qualitativo, valorizaram-se as interações com os valores, experiências e desafios que são mais bem interpretados pelas lentes simbólicas e não métricas de pesquisa 12 .

Para tanto, a mesma equipe de pesquisadoras do programa investiu na condução da pesquisa. Participaram das entrevistas 7 profissionais da saúde e da educação com experiência no processo de apoio, suporte e orientação às escolas e creches do Município de São João de Meriti engajados na inclusão escolar de crianças com deficiência e que estiveram presentes nos dias em que os grupos se 
desenvolviam. Foram entrevistados: uma psicóloga, uma fisioterapeuta, uma fonoaudióloga, uma assistente social e três pedagogas.

O recurso à entrevista semiestruturada, com roteiro temático, teve por base uma questão provocadora: "Fale como foi a experiência da equipe com a presença do grupo de pesquisadoras e famílias aqui no CAEE".

Tal questão permitiria provocar os sentidos, baseados nas interpretações e compreensões dos profissionais do CAAE envolvidos na experiência do Programa JUNTOS, sobre a experiência de engajamento com o processo de inclusão das crianças com síndrome congênita do vírus Zika.

As entrevistas foram submetidas aos princípios do método de interpretação de sentidos 15. Para esse método, importam o contexto, as razões e as lógicas empreendidas que evocam ações e interações entre grupos e instituições. As lentes teóricas para olhar para esses sentidos advieram da perspectiva bourdieusiana 16 , considerando os capitais simbólicos e referências que estruturam e são estruturadas em um determinado campo de disputas por hegemonia, afirmação e reconhecimento. Inicialmente, elaborou-se uma estrutura de análise constituída pela questão central provocadora da entrevista, articulando com extratos das falas dos participantes da pesquisa. Em seguida, foram identificadas as ideias centrais e os sentidos a elas subjacentes, proporcionando ao final a organização de eixos para a elaboração de uma síntese interpretativa, articulando a discussão sobre inclusão, integralidade e intersetorialidade na relação educação e saúde.

Assim, à luz da perspectiva teórica de Pierre Bourdieu, nos entendimentos sobre campo e práticas sociais, relacionando ao contexto da experiência do Programa JUNTOS, estava em jogo o capital simbólico sobre inclusão, deficiência e relações de competência. A chegada de "profissionais e pesquisadoras” do programa evocaria dimensões simbólicas fortes sobre o desconhecimento provocado sobre a epidemia de Zika e o nascimento de crianças com a síndrome congênita do vírus Zika. A imagem de que viria desses profissionais um repertório para dialogar com os desafios da inclusão justifica a perspectiva de círculos de competência em disputa, em campos profissionais em relação. Faz parte desse campo levar em conta os repertórios anteriores sobre os desafios de trabalhar com crianças deficientes na educação, as urgências de apoios construídos de forma compartilhada, os desafios e as cobranças sobre a presença das mães e o saber compartilhado entre técnicos e pessoas comuns.

\section{Resultados e discussão}

\section{Autorreflexões sobre a prática profissional}

Tomando-se o ambiente escolar como um campo 16, é importante refletir sobre as atuações dos profissionais ali inseridos - que determinam e são determinadas pelas interlocuções, ações e disputas. $\mathrm{Na}$ análise e interpretação de sentidos, emergiram por parte dos atores posicionamentos em que disputas, conflitos e elaborações se fizeram presentes considerando as relações entre saúde e educação.

Para Bourdieu 16, o campo é o espaço social capaz de repulsar, traduzir ou transformar as demandas externas, uma rede de relações objetivas dentre posições, um espaço de lutas em que os agentes tomam lugar, um sistema no qual essas são apreendidas - portanto, social e historicamente colocadas - influenciando as tomadas de decisões. Nas escolas, assim como em outros settings de cuidados à criança deficiente, há conflitos e tensões de natureza grupal e profissional, pois, hegemonicamente, a escola representa a institucionalização dos conhecimentos especializados, com dificuldades em lidar com as diferenças, em um olhar integral e integrador, promotor de inclusão.

É interessante observar como se deu a primeira aproximação entre os pesquisadores do programa e os profissionais do CAEE e como a rede entre eles e as famílias foi sendo tecida. Na primeira fase de validação do Programa JUNTOS, o grupo piloto, realizado no centro da cidade do Rio de Janeiro (Figura 2), era composto por mulheres moradoras da cidade de São João de Meriti. Seus filhos estavam começando a frequentar o CAEE e em uma das sessões do programa em que deveriam convidar membros de sua comunidade para discutir temas importantes para o grupo, tal convite foi feito para profissionais da instituição. Essas profissionais puderam ver pela primeira vez as mães em um lugar diferente do habitual: "Ai surgiu o convite pra participar desse evento (...) a minha expectativa é que seria uma palestra, uma coisa mais formal que eu estaria indo para ouvir sobre o Zika vírus. Quando eu cheguei, fiquei 
muito surpreendida porque vi que tinham voluntários com as crianças, onde eu vi três das nossas mães muito participativas" (Petúnia).

Alguns aspectos relativos à maternidade e ao cuidado dessas crianças, destacando o protagonismo feminino frente à epidemia, podem ser analisados como um dos sentidos emergentes, juntamente com a ideia de que faz parte do campo "aprender, ter palestras". Moreira et al. 17 destacam como as mães de crianças com microcefalia agilizaram o debate público ao acionar o Estado e a mídia cobrando direitos. Scott et al. 18 apontam que, frente às dificuldades encontradas e reencontradas pelas famílias, são as associações de mães que aberta e expressamente se iluminam perante as necessidades de seus filhos(as) na interface da deficiência e das doenças raras.

Outro aspecto diz respeito à ausência de ações efetivas por parte do Estado, no pós-epidemia, que apoiariam o crescimento dessas crianças, que sobrevivendo aos anúncios de inviabilidade, estavam demandando ações efetivas de inclusão em creches e escolas. As questões colocadas por essas crianças vivendo com condições de saúde complexas e deficiências já foi assinalada em outros estudos como uma responsabilidade para uma linha de cuidados 18. Nesse nicho, inclui-se a necessidade de capacitações efetivas, que ganham por vezes a nomeação de "palestras", e que no caso acima surpreendem por representar o lugar assumido pelas mães como possuidoras de um conhecimento, tornando-se especialistas da experiência ${ }^{19}$. Nesse caso, elas desenvolvem esse conhecimento não só em função da necessidade de cuidar de seus filhos, mas porque promovem entre si redes de apoio.

As mães de crianças com a síndrome congênita do vírus Zika no Rio de Janeiro formaram uma associação chamada Lótus, que tem se destacado pela presença constante nos campos do debate público, seja com o executivo ou judiciário, mas também com o universo acadêmico. Algumas dessas mães, como destacou nossa entrevistada acima, fizeram parte do grupo piloto desta pesquisa no Rio de Janeiro. Já antecipando a necessidade de inclusão social e escolar, essas mães foram em busca dos profissionais do CAEE, convidando-as a participar das atividades do Programa JUNTOS, certas de que também era uma causa pela qual deveriam trabalhar de maneira articulada.

Após esse primeiro encontro, foi estratégico aproximar o grupo de pesquisadoras em parceria com o CAEE, contando com as mães que participaram do piloto para esclarecer quais seriam os objetivos e a proposta do programa.

"A forma que vocês chegaram foi bem transparente, (...) Mas à medida que a coisa vai materializando, a confiança foi crescendo. Não vi muita resistência não, pelo contrário, como a gente fica aqui de forma meio que isolada, ter uma visibilidade, vir alguém de fora que tem um olhar diferente (...) não foi uma parceria que a gente buscou, (...) Foi uma coisa que veio pelas mães, isso também deu uma diferença. Existe um olhar e uma respeitabilidade" (Petúnia).

As trocas, amalgamadas pela confiança e engendradas desde o início, foram determinantes para o processo. Essas trocas são simbólicas, operando como capital simbólico 20 que transcende a lógica utilitarista e econômica. Recorrendo à Teoria da Dádiva de Mauss 21,22, como um modelo interpretativo muito caro à discussão sobre alianças nas sociedades contemporâneas, destacamos a tríplice obrigação que faz parte do sistema de construção do vínculo social: dar-receber-retribuir. O que circulam são bens simbólicos ou materiais que oferecidos geram a obrigação de retribuição, inerente ao mecanismo de aceitação do presente oferecido. Esse circuito baseado na reciprocidade possibilita a criação de redes de sociabilidade, confiança e, na área da saúde, fazem circular bens de cuidado 23.

O Programa JUNTOS provocou essa lógica primordial. As famílias receberam um convite para participar do programa sem saber ao certo como se daria, então puderam oferecer presença e confiança de que seria algo pertinente. O programa, por sua vez, ofereceu um espaço que ia além do tão comum prescritivo, um lugar de acolhimento em que elas ocupavam um papel central. Diante disso, elas retribuíram convidando os profissionais do CAEE que já se encontravam inseridos em um sistema de trocas com essas famílias. Pode-se inferir que fizeram parte desses bens trocados: a confiança, o conhecimento e a esperança na inclusão das crianças.

Um novo circuito envolvendo diferentes atores foi construído, com o CAEE oferecendo o espaço para o programa, recebendo uma série de bens que não são apenas materiais:

"Só em saber, ah o Fernandes Figueira tá lá, maior visibilidade da secretaria de educação, do pessoal para um olhar melhor pra essas crianças pra essas famílias, ai o Fernandes figueira veio complementando com essa questão que a gente pode colocar mais brinquedos pras crianças, com a verba que veio, isso também deixou as mães mais animadas né?" (Orquídea). 
Cabe destacar - pelos sentidos que emergem das relações entre atores diferencialmente situados, com capitais diferentes de poder simbólico - os movimentos que esse cenário de ações provoca. Ou seja, um instituto de referência promove por intermédio do capital simbólico 20 acumulado uma série de outras possibilidades de olhar para as crianças com síndrome congênita do vírus Zika e suas famílias. Se trabalhar com crianças com deficiências é ter dificuldades não apoiadas não era novidade, o novo veio em função de um arranjo de atores que conjuga instituições internacionais de forte capital científico, uma instituição nacional como o IFF/Fiocruz, que confere (e fortalece) às mães e voluntários, com alto capital de reconhecimento na oferta de conhecimento, formação de redes de familiaridade e troca afetiva, em uma perspectiva de instauração de vínculos e trocas sociais 21 .

Diferentemente da caridade, da qual não se espera nada em troca de quem recebe e nem se abre essa possibilidade retirando do outro qualquer chance de retribuição, o acionamento da dádiva faz reconhecer o espaço fundamental das famílias nesse contexto do cuidado, e um novo circuito de trocas foi capaz de circular. Destaca-se a importância que é dada ao fato de o convite ter sido feito pelas mães - nas palavras da entrevistada é visto como respeitabilidade, credibilidade, algo fundamental para que o circuito se forme.

"A escola não consegue muito ver que precisa também dessa família perto, normalmente a escola diz que quer a família bem longe, e se a família 'tiver longe, principalmente nos casos das crianças com deficiência, não vai ter resultado, ...porque a família também muitas vezes não acredita que seja possível fazer algum trabalho com aquela criança (...) oportunidade pra... refletir o nosso papel na atenção às famílias, porque antes isso, assim, não era muito visto pra equipe do CAEE” (Dália).

Não só a presença do grupo de pesquisa produziu na equipe efeitos relacionados à prática, mas a maneira como essas trocas simbólicas se deram possibilitou uma ressignificação dos lugares e das relações estabelecidas.

“...É claro que tudo que é novo a gente fica assim naquela expectativa, inicialmente eu vi... que a equipe gostaria de estar mais por dentro [do projeto]... Então acho que inicialmente nesse primeiro contato, acho que isso foi um pouco questionado (...) porque às vezes as coisas ficam muito burocráticas e limitadas, restritas a certos espaços. E a gente sabe que as deficiências, né? Elas nos, nos colocam assim muito mais desafios (...) A gente tá lidando mais proximamente com as mães, né? É, e com as famílias de uma certa forma" (Rosa).

Ao receber pesquisadores com uma proposta diferenciada daquela habitual da escola, a saber, a de desenvolvimento de ações de promoção de saúde para famílias de crianças com deficiência, pode emergir um sentido de soma, reflexão e aprendizado.

"Nós... aqui no CAEE enquanto equipe, entendemos que foi uma excelente oportunidade pra... refletir o nosso papel na atenção às famílias, porque antes isso, assim, não era muito visto pra equipe do CAEE... E assim, a, é, essa pesquisa veio mesmo pra somar. E pra mostrar pra gente a importância também de também dar assistência pra essa família" (Dália).

A presença dos pesquisadores e as ações ali desenvolvidas acabaram por produzir na equipe uma reflexão sobre suas práticas, particularmente com as famílias, em um campo de disputas por autoridades. Emergem sentidos sobre a troca de experiências, de informações e conhecimento que permitiu abrir novos caminhos, ampliando os horizontes e contribuindo para o desenvolvimento daqueles envolvidos no processo.

\section{Intersetorialidade e inclusão}

Analisando os desafios apontados, pode-se inferir que a discussão sobre inclusão mais uma vez se beneficia da análise de Bourdieu sobre campo. A disputa entre espaços sociais que se organizam em torno de eixos da educação e saúde se configura como círculos de poder simbólico e disputa de competências em que aquilo que está em jogo são definições sobre como incluir crianças diferentes, oferecendo-lhes condições de cuidado, aprendizagem e proteção social.

Tomou-se como pressuposto que a concepção de saúde e a educação estão intimamente articuladas e são complementares e essenciais para o progresso das ações e cuidado em saúde, mas nem por isso deixam de existir disputas. Destaca-se que saúde e educação não podem ser dissociadas, caminham juntas e se articulam enquanto práticas sociais para favorecer a qualidade de vida e inclusão social, no entanto é preciso investir em processos permanentes de pactuação, negociação e, por que não dizer, formação permanente. 
Estudos indicam a existência de uma estreita relação entre condições de saúde infantis, qualidade de vida e promoção de saúde dos cuidadores 23,24,25. A literatura aponta para uma elevada proporção de mães como cuidadoras, seguidas por pais e avós. Tais resultados sugerem a influência de fatores culturais e sociais, em que se observa o dever específico da mulher de exercer o papel de cuidadora da prole. Enfrentar essas iniquidades de gênero, significa reconhecer a presença das cobranças sobre a atuação das mães na adaptação de crianças com deficiências e outras complexidades de saúde no interior das escolas.

O cuidado se liga intrinsicamente à interdependência e sempre é dirigido a alguém 26. Quando essas crianças estão nas escolas e nos serviços de saúde, predominam as mulheres nesse trabalho de cuidado. Muito embora se configure como predominantemente feminino, não pode ser encarado como algo da ordem da natureza da mulher, mas sim uma construção social, um trabalho "generificado". Ele envolve outras mulheres pagas para cuidar, assim como o trabalho invisível das que possuem laços de consanguinidade - mães, tias, avós e irmãs mais velhas - nessa função. Como nos lembram Hirata \& Kergoat 27, a divisão sexual do trabalho decorre das relações sociais, e o cuidado nelas se inclui. No caso das crianças com deficiências, vivendo com condições crônicas e complexas de saúde, no qual se incluem as crianças com síndrome congênita do vírus Zika, muitas são as redes de cuidado e interdependência que contrastam por vezes com o estigma, gerador de solidão e abandono.

As entrevistadas destacaram a preocupação com essas famílias, pela proximidade com elas, que semanalmente passaram a frequentar o CAEE a fim de participar dos grupos.

"Esse trabalho [o projeto] deu uma visibilidade para a importância no relacionamento com as famílias... esse grupo [de pesquisa] aqui no CAEE possibilitou o diálogo com as famílias... é muito importante elas se informarem... porque falar da deficiência ainda é um tabu... é importante ter um espaço para discutir isso..." (Petúnia).

Essa reflexão remete ao atual enfoque da promoção da saúde que é tanto social - considerando-a uma política - quanto um conceito ampliado, com o desenvolvimento de competências, propiciando uma cultura de saúde mediante a redução do risco, o fortalecimento da intersetorialidade e o reforço do poder do cidadão.

No Município de São João de Meriti, 34o no ranking do Índice de Desenvolvimento Humano (IDH) do Estado do Rio de Janeiro 28, a promoção da saúde representa um desafio para o cuidado, diante da necessidade de transformação das condições de vida da população. Importante assim que as ações se voltem para uma construção coletiva entre os profissionais e a comunidade, que busca responder de maneira mais efetiva às suas reais necessidades.

"Então a gente 'tá tentando de toda maneira aquela parceria com a Saúde, e a gente pretende que seja da mesma maneira, nós 'tamos de porta aberta pra isso" (Lírio).

Mesmo desejada, a parceria para trabalhar de maneira intersetorial é um desafio, exigindo o compartilhamento de espaços e conhecimentos permitindo o desenvolvimento de novas linguagens, saberes e conceitos. A posição de disputa entre os agentes se relaciona também ao capital simbólico e, no caso da experiência em tela, também ao capital material. Há que pensar à luz de Bourdieu o que significa a potência de uma experiência que coloca “juntas”, mães, avós - pessoas comuns, mas repletas de autoridade de experiência - e um grupo de professores de um município pobre do Rio de Janeiro, com duas instituições que encarnam em seus profissionais símbolos de status e competência; o IFF/ Fiocruz e a LSHTM.

O diálogo intersetorial demanda desejar a visão do outro e sua contribuição para a construção de soluções para os problemas levantados. Todavia, pode ser uma importante estratégia de reconstrução da esfera pública. Nesta direção, tanto a saúde quanto a educação devem poder ser pensadas de forma mais integrada.

"Na área [geográfica] onde estamos... a gente tem a questão da vulnerabilidade social que é assim, gritante, então a gente precisaria também ter um trabalho com as famílias, muito mais amplo do que atender simplesmente as questões das crianças com deficiência" (Dália).

Quando se fala de sujeitos em vulnerabilidade, devem ser considerados fatores que transcendem o biológico ${ }^{3}$. Retorna-se novamente ao conceito de vulnerabilidade, pois ao refletir sobre as famílias acompanhadas pela equipe do CAEE, não é possível desconsiderar o contexto de vida e como isso pode contornar suas formas de expressividade, exercendo influências sobre as maneiras como se posicionam na sociedade e como se enxergam. 
Fica clara a necessidade pela equipe do CAEE de apoiar o desenvolvimento de capacidades humanas, seja individualmente, seja nas famílias e no território, valendo-se da concepção que admite a existência de ativos nos indivíduos, e do benefício de fortalecê-los para o enfrentamento de situações de vulnerabilidade pelos sujeitos. Assim, vulnerabilidade e capacidade estão inseridas em igual processo de luta por superação, portanto se pode afirmar que nelas reside o germe para o seu próprio enfrentamento.

Compreendendo o cotidiano escolar como um espaço social, o pensamento de Santos 29 e Santos \& Meneses 30 nos leva a refletir que a escola, com todos os seus agentes, deve possibilitar a articulação entre os saberes, no encontro entre o senso comum e o conhecimento científico. Reconhecer o senso comum e o conhecimento científico como saberes e fazeres legítimos é buscar igualar e democratizar as relações de poder que se fazem presentes no cotidiano social e, sem isso, a emancipação não se faz possível.

"Quando eu cheguei lá fiquei muito surpreendida... eu vi três das nossas mães muito participativas, aquilo me deu uma visão muito legal, eu falei assim: "gente, como elas estão integradas, elas falam, conversam, já se apoderaram dessa situação, já pegaram como bandeira mesmo pra vida delas, e fiquei feliz com aquilo" (Begônia).

Porém, não há como compreender emancipação sem dialogar com assimetrias, lutas simbólicas, e aqui Bourdieu auxilia a entender que cada campo prescreve seus próprios valores e princípios de regulação. No campo social, a interação dos indivíduos se dá por meio da produção de relações de pertencimento, conflito, negociação e diferenciação, e ela se atualiza nos momentos em que podem conviver uns com os outros de acordo com a situação vivida e as exigências colocadas aos sujeitos. Assim sendo, para esse autor, a coexistência de forças e lutas opera tanto no eixo da conservação quanto no da transformação.

O processo de integração não é fácil e rapidamente alcançado apenas pela instauração de uma lei. Exige uma série de medidas gradativas de reformulação do ensino que começa pelos já citados currículos e métodos, e vai além. A presença de crianças com deficiência na rede regular de ensino exige dos profissionais conhecimentos produzidos em diferentes áreas para gerar um saber interdisciplinar, indispensável ao sucesso da inclusão.

“...É, tem que andar de, junto, Saúde e Educação, mas infelizmente é difícil, é, a gente... tenta de toda maneira andar junto" (Lírio).

Dessa maneira, pode-se considerar que, para as crianças com deficiências, a integralidade se realiza como dimensão importante na inclusão delas em espaços educacionais, que é delas por direito. Um projeto de inclusão 31 deve integrar contribuições das diversas áreas de conhecimento na busca de uma linha de ação comum. Por conseguinte, estudos que trazem como referência a abordagem social sobre a deficiência se mostram cada vez mais necessários ao oferecerem subsídios às reivindicações quanto às formas de valorização, respeito e garantia dos direitos de crianças com deficiência e sua visibilidade social 32,33.

\section{Considerações finais}

A análise dos sentidos das interações simbólicas entre competências na experiência do Programa JUNTOS levou a reconhecer nos circuitos de troca uma relação entre o conhecimento oferecido e a interpretação que o projeto e suas ações provocam na necessidade de rever práticas, conceitos e posições na relação com os serviços de saúde, o saber das mães e o componente da inclusão educacional. Ou seja, as dimensões partiram da autorreflexão sobre a prática do educador quando atores que em geral não fazem parte da escola - profissionais da atenção especializada - se apresentam oferecendo apoio, conhecimento e outros olhares sobre o saber das mães que não seja apenas como acompanhantes.

Ao convidarem os profissionais do CAEE para conhecer o Programa JUNTOS, essas mães se reapresentaram para esses profissionais como protagonistas, reafirmando o que esperam sobre o cuidado de suas crianças. O Programa JUNTOS assumiu que os especialistas nem sempre são os que têm mais a dizer sobre as crianças, e com isso possibilitou que a relação que já existia passasse a ser percebida de maneira diferente.

Logo, tanto os profissionais passaram a ouvir as famílias de outro lugar quanto elas começaram a escutar suas próprias vozes, tantas vezes abafadas pelo discurso da técnica, e puderam repensar o 
lugar da escola na vida de seus filhos tendo espaço, tempo e apoios para isso. Essa aproximação se revelou essencial à transição das crianças com síndrome congênita do vírus Zika, que tendem a ocupar hospitais e clínicas, para o ambiente da escola, que é por excelência "lugar de criança".

Tendo em vista as dificuldades de as crianças com deficiência se integrar ao grupo escolar, devem ser enfrentadas as barreiras simbólicas dos estigmas que antecipam discriminações negativas e inviabilidades. Quando se amplia a rede de interações, maiores são as possibilidades de trocas e de aprendizagem, de valorização das práticas. Diante dos desafios relacionados às crianças com deficiência, faz-se necessário gerar mecanismos de confiança e troca entre saberes da saúde, da educação e das famílias. Há que se questionar como acionar o que já existe em políticas públicas para que possa incorporar programas como esse, em que as famílias e suas crianças são de fato protagonistas dessas relações. Somente dessa maneira é possível falar sobre inclusão e integralidade.

\section{Colaboradores}

M. R. C. Sá participou da concepção, escrita do artigo, revisão crítica do conteúdo intelectual e aprovação final da versão a ser publicada. A. C. D. Vieira, B. S. M. Castro e O. Agostini participaram da escrita do artigo. T. Smythe participou da concepção e revisão do artigo. H. Kuper e M. E. L. Moreira participaram da revisão e aprovação final da versão a ser publicada. M. C. N. Moreira participou da escrita do artigo, revisão crítica do conteúdo intelectual e aprovação final da versão a ser publicada.

\section{Informações adicionais}

ORCID: Miriam Ribeiro Calheiros de Sá (00000002-3972-0377); Ana Carolina Dias Vieira (0000-0002-3649-5696); Barbara S. Madeira Castro (0000-0003-3185-3703); Olivia Agostini (0000-0002-1128-0568); Tracey Smythe (00000003-3408-7362); Hannah Kuper (0000-00028952-0023); Maria Elisabeth Lopes Moreira (00000002-2034-0294); Martha Cristina Nunes Moreira (0000-0002-7199-3797).

\section{Agradecimentos}

À equipe do Centro de Atendimento Educacional Especializado por todo apoio e receptividade. À Wellcome Trust (no 206719/Z/17/Z) pelo financiamento.

\section{Referências}

1. Secretaria de Vigilância em Saúde, Ministério da Saúde. Monitoramento integrado de alterações no crescimento e desenvolvimento relacionadas à infecção pelo vírus Zika e outras etiologias infecciosas. Boletim Epidemilógico $2018 ; 49(6)$. http://portalarquivos2.saude. gov.br/images/pdf/2018/fevereiro/20/2018003-Final.pdf.

2. Pedi VD, Garcia MHO, Carmo GMI, Leal MB, Garcia LP. Síndrome congênita associada à infecção pelo vírus Zika no Brasil: descrição da distribuição dos casos notificados e confirmados em 2015-2016. Epidemiol Serv Saúde 2018 27:e2017473.

3. Moreira MEL, Goldani MZ. A criança é o pai do homem: novos desafios para a área de saúde da criança. Ciênc Saúde Colet 2010; 15:321-7.

4. Moreira MCN, Albernaz LV, Sá MRC, Correia RC, Tanabe RF. Recomendações para uma linha de cuidados para crianças e adolescentes com condições crônicas complexas de saúde. Cad Saúde Pública 2017; 33:e00189516.

5. Carmo ME, Guizardi F. O conceito de vulnerabilidade e seus sentidos para as políticas públicas de saúde e assistência social. Cad Saúde Pública 2018; 34:e00101417.

6. Diniz D. O legado da Zika. Correio Braziliense 2017; 19 nov.

7. Brasil. Lei no 8.080, de 19 de setembro de 1990. Dispõe sobre as condições para a promoção, proteção e recuperação da saúde, a organização e o funcionamento dos serviços correspondentes e dá outras providências. Diário Oficial da União 1990; 20 set.

8. Constituição da República Federativa do Brasil. Brasília: Senado Federal; 1988.

9. Mattos RA. Os sentidos da integralidade: algumas reflexões acerca de valores que merecem ser defendidos. In: Pinheiro RE, Mattos RA, organizadores. Os sentidos da integralidade na atenção e no cuidado à saúde. Rio de Janeiro: Instituto de Medicina Social, Universidade do Estado do Rio de Janeiro/ABRASCO; 2001. p. 39-64. 
10. Paula KA, Palha PF, Protti ST. Intersetorialidade: uma vivência prática ou um desafio a ser conquistado? Interface (Botucatu) 2004; 8:33148.

11. Jurdi APS, Teixeira PA, Sá CSC. Vulnerabilidade sócioambiental e o cuidado na primeira infância: o olhar da terapia ocupacional para o trabalho em creche. Rev Ter Ocup 2017; 28:281-9.

12. Alves RLC, Fleischer S. "O que adianta conhecer muita gente e no fim das contas estar sempre só?" O desafio da maternidade em tempos de Síndrome Congênita do Zika Vírus. Revista Anthropológicas 2018; 29:6-27.

13. Sá MRC, Ribeiro CTM, Almeida PT, Cavalcanti NC, Santos FL. Reflexões sobre a rede de atenção especializada em reabilitação de crianças e adolescentes com condições crônicas de agravos à saúde. Cad Educ Saúde Fisioter 2015; 2:67-77.

14. Silva KL, Rodrigues AT. Ações intersetoriais para promoção da saúde na Estratégia Saúde da Família: experiências, desafios e possibilidades. Rev Bras Enferm 2010; 63:762-9.

15. London School of Hygiene \& Tropical Medicine; International Center for Evidence in Disability. Getting to know cerebral palsy. 2014. http://disabilitycentre.lshtm.ac.uk/ files/2013/06/Getting-to-know-cerebral-pal sy-v1-hires.pdf (acessado em 11/Abr/2019).

16. Bourdieu P. Esboço da teoria da prática. In: Ortiz R, organizador. Pierre Bourdieu: sociologia. 2a Ed. São Paulo: Editora Ática; 1994. p. 46-81.

17. Moreira MCN, Mendes CHF, Nascimento M. Zika, protagonismo feminino e cuidado: ensaiando zonas de contato. Interface (Botucatu) 2018; 22:697-708.

18. Scott RP, Lira LC, Matos SS, Souza FM, Silva ACR, Quadros MT. Itinerários terapêuticos, cuidados e atendimento na construção de ideias sobre maternidade e infância no contexto da Zika. Interface (Botucatu) 2018; 22:67384.

19. Borkman T. Experimental knowledge: a new concept for the analysis of self-help groups. Social Service Review 1976; 50:445-56.

20. Bourdieu P. Espaço social e espaço simbólico. In: Bordieu P, organizador. Razões práticas. Sobre a teoria da ação. Campinas: Papirus; 1996. p. 13-27.

21. Mauss, M. "Ensaio sobre a dádiva: forma e razão da troca nas sociedades arcaicas” em Sociologia e Antropologia. São Paulo: Cosac Naif; 2003.
22. Moreira MCN. Contra a desumanização da medicina: crítica sociológica das práticas médicas modernas. Ciênc Saúde Colet 2005; 10:780-8.

23. Ryan JM, Allen E, Gormley J, Hurvitz EA, Peterson $\mathrm{M}$. The risk, burden, and management of non-communicable diseases in cerebral palsy: a scoping review. Dev Med Child Neur 2018; 60:753-64.

24. Camargos ACR, Lacerda TTB, Barros TV, Silva GC, Parreiras JT, Vidal THJ. Relação entre independência funcional e qualidade de vida na paralisia cerebral. Fisioter Mov 2012; 25:8392.

25. Souza JM, Machado FRC, Antunes PP, Santos AC, Levandoswki DC, Oliveira Junior AA. Qualidade de vida e sobrecarga de cuidadores de crianças com paralisia cerebral. Rev Bras Promoç Saúde 2018; 31:1-10.

26. Hirata HS. O desenvolvimento das políticas de cuidados em uma perspectiva comparada: França, Brasil e Japão. Revista Política Pública 2012; (n esp):283-90.

27. Hirata HS, Kergoat D. Novas configurações da divisão sexual do trabalho. Cad Pesqui 2007; 37:595-609.

28. Instituto Brasileiro de Geografia e Estatística. Censo demográfico 2010: características gerais da população, religião e pessoas com deficiência. Rio de Janeiro: Instituto Brasileiro de Geografia e Estatística; 2010.

29. Santos BS. Renovar a teoria crítica e reinventar a emancipação social. São Paulo: Boitempo; 2007.

30. Santos BS, Meneses MP. Epistemologias do Sul. São Paulo: Editora Cortez; 2010.

31. Kafrouni R, Pan MAGS. A inclusão de alunos com necessidades educativas especiais e os impasses frente à capacitação dos profissionais da educação básica: um estudo de caso. Interação Psicol 2001; 5:31-46.

32. Baglieri S, Valle JW, Connor DJ, Gallagher DJ. Disability studies in education: the need for a plurality of perspectives on disability. Remedial and Special Education 2011; 32:267-78.

33. Valle JW, Connor DJ. Ressignificando a deficiência: da abordagem social às práticas inclusivas nas escolas. Porto Alegre: Editora AMGH; 2014. 


\section{Abstract}

The experience with an intervention program conducted in an educational institution and targeted to families of children with congenital Zika syndrome, which includes multiple disabilities, revealed the challenges and strides with the entry of these families in the school system. This article aimed to explore the findings from a study conducted after the conclusion of an intervention program, using semi-open interviews with professional staff at the institution and the possible contributions towards establishing inter-sector relations aimed at school inclusion of children with disabilities. A change was seen, as a result of the program, in the relationship between the families and the professionals at the educational institution, whereby the families had room to voice their fears and discuss the school's role in the lives of their children with disabilities. The professionals thus came to see the families taking a more active stance. This experience can favor other services and municipalities that seek school inclusion for children and adolescents with disabilities, as well as their social inclusion and that of their families.

Child; Zika Virus; Disabled Persons; Intersectorial Collaboration

\section{Resumen}

A partir de la experiencia de un programa de intervención para familias de niños con el síndrome congénito del virus Zika, que incluye múltiples discapacidades, en una institución educativa se observaron los desafíos y logros que se consiguieron tras la entrada de esas familias en el sistema escolar. El objetivo de este artículo fue analizar los resultados de la investigación realizada, tras la conclusión de un programa de intervención, a través de entrevistas semiabiertas con profesionales de la institución, así como las posibles contribuciones en la construcción de relaciones intersectoriales, con el fin de la inclusión escolar de niños con discapacidad. Es posible observar el cambio provocado por el programa en la relación entre las familias y los profesionales de la institución educativa, debido a que las familias contaron con un espacio para exponer sus recelos y discutir el papel de la escuela en la vida de niños con discapacidad. De esta forma, los profesionales pasaron a ser vistos desde una posición más activa. Se cree que esta experiencia puede favorecer a otros servicios y municipios que busquen la inclusión escolar de niños y adolescentes con discapacidad, así como su inclusión social y la de sus familias.

Niño; Virus Zika; Personas con Discapacidad; Colaboración Intersectorial
Recebido em 05/Dez/2018

Versão final resubmetido em 27/Abr/2019

Aprovado em 03/Jun/2019 